\title{
Production of Cellulose Nanofibers from Olive Tree Harvest-A Residue with Wide Applications
}

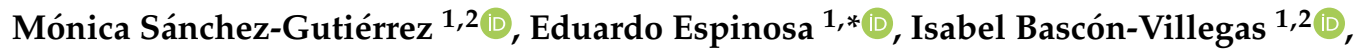 \\ Fernando Pérez-Rodríguez ${ }^{2}$, Elena Carrasco ${ }^{2}$ and Alejandro Rodríguez ${ }^{1, *(D)}$ \\ 1 Bioagres Group, Chemical Engineering Department, Universidad de Córdoba, Marie-Curie Building, \\ 14014 Córdoba, Spain; v02sagum@uco.es (M.S.-G.); q12bavii@uco.es (I.B.-V.) \\ 2 Food Science and Technology Department, Universidad de Córdoba, Darwin Building, 14014 Córdoba, \\ Spain; b42perof@uco.es (F.P.-R.); bt2cajie@uco.es (E.C.) \\ * Correspondence: eduardo.espinosa@uco.es (E.E.); a.rodriguez@uco.es (A.R.)
}

Received: 20 April 2020; Accepted: 11 May 2020; Published: 13 May 2020

\begin{abstract}
With the aim of identifying new sources to produce cellulose nanofibers, olive tree pruning biomass (ОTPB) was proposed for valorization as a sustainable source of cellulose. OTPB was subjected to a soda pulping process for cellulose purification and to facilitate the delamination of the fiber in the nanofibrillation process. Unbleached and bleached pulp were used to study the effect of lignin in the production of cellulose nanofibers through different pretreatments (mechanical and TEMPO-mediated oxidation). High-pressure homogenization was used as the nanofibrillation treatment. It was observed that for mechanical pretreatment, the presence of lignin in the fiber produces a greater fibrillation, resulting in a smaller width than that achieved with bleached fiber. In the case of TEMPO-mediated oxidation, the cellulose nanofiber characteristics show that the presence of lignin has an adverse effect on fiber oxidation, resulting in lower nanofibrillation. It was observed that the crystallinity of the nanofibers is lower than that of the original fiber, especially for unbleached nanofibers. The residual lignin content resulted in a greater thermal stability of the cellulose nanofibers, especially for those obtained by TEMPO-mediated oxidation. The characteristics of the cellulose nanofibers obtained in this work identify a gateway to many possibilities for reinforcement agents in paper suspension and polymeric matrices.
\end{abstract}

Keywords: olive tree harvest; lignocellulose nanofibers; circular economy; valorization; pretreatments; high-pressure homogenization

\section{Introduction}

The concept of the circular economy-a system where waste generation is minimized by reintroducing residues and by-products into the production cycle-can be applied, to a large extent, to production processes that use natural resources. This is one of the bases that support the so-called bioeconomy, the need for the integral valorization of natural resources. In Europe, agriculture constitutes approximately $63 \%$ of the total biomass supply; forestry, about $36 \%$; and fisheries, less than $1 \%$ [1]. It is therefore essential to focus on the recovery of waste generated by the agricultural sector in order to guide the economic strategy towards a circular economy and bioeconomy.

Spain is the leading country in olive and olive oil production with an average annual output of 9.8 million tons of olives, more than five times that of the second largest producer, Italy, with 1.8 million tons per year [2]. Spain represents $47 \%$ of worldwide olive production and $72 \%$ of European production. As consequence of this production, after harvest, a large number of different types of lignocellulosic materials are generated (pruning, leaves, stones, pomace, etc.), which generally have no industrial application and must be discarded. It is estimated that for the production of one $\mathrm{kg}$ of fruit, 
more than $0.8 \mathrm{~kg}$ of waste is generated, meaning more than 7.5 million tons of olive harvest waste per year, waste that could be valorized in Spain. Olive tree pruning biomass (OTPB), in common with any lignocellulosic material, mainly consists of cellulose, lignin and hemicellulose; and other non-structural minority compounds such as pigments, proteins, ashes, etc. This biomass can be fractionated into its various components by means of biorefinery processes. This fractionation of the OTPB into its lignocellulosic components has been widely studied by the scientific community, testing its application as a source of sugar [3], substrate for ethanol production [4], lignin [5], energy [6], building materials [7] and cellulose fibers for paper and cardboard production [8].

One of the most interesting avenues for the valorization of the agricultural residues is the production of nanocellulose as an alternative to wood sources [9]. Nanocellulose presents unique properties such as a high surface area, unique optical properties, lightweightness, stiffness and a high strength, in addition to its inherent properties in common with cellulose (renewable, biodegradable and sustainable) [10]. These properties allow the possibility of using this nanomaterial in many industrial sectors, expecting to reach a global turnover around 10,000 M€ in 2020 [11]. The wide range of applications of nanocellulose-based materials include the paper and cardboard industry [12], electronic devices [13], energy [14], cosmetics [15], composites [16], wastewater treatment [17], catalysts [18], construction [19], drug carriers [20] and biomedicine [21]. The use of agricultural residues, such as OTPB, as a source for the local, renewable and sustainable production of nanocellulose will allow countries with insufficient forest resources to produce these high value-added products.

Cellulose nanofibers (CNFs), also known as nanofibrillated cellulose, are one of the existing types of nanocellulose (along with cellulose nanocrystals and bacterial cellulose). CNFs are long (several microns), flexible (presenting both types of cellulose region, crystalline and amorphous), nanometric (1-100 $\mathrm{nm}$ in width) and are extracted from cellulosic fibers by mechanical methods [22]. The mechanical treatment aims at the isolation of the cellulose nanofibers by the delamination of the fibers. Several mechanical treatments have been studied, including high pressure homogenization [23], twin-screw extrusion [24], micro-fluidization [25] and ultrafine-friction grinding [26], the most commonly used. One of the great disadvantages of these treatments is the large number of passes that the fibers have to undergo and the long time required to produce delamination. Therefore, to facilitate and increase the effectiveness of the treatment, fibers are subjected to a previous process, known as pretreatment. Likewise, there are many pretreatments, but the most widely used and most effective are mechanical pretreatment [27], enzymatical pretreatment [28], TEMPO-mediated oxidation [29] and surface functionalization [30]. To study the effectiveness of the different treatments, it is crucial to determine the chemical composition of the source, to optimize the process of fiber obtention and to adequately characterize the final product.

In this work, olive tree pruning biomass has been valorized as a lignocellulosic source for the obtention of cellulose nanofibers as a high value-added product. The suitability of the chemical composition of the raw material and the fiber in cellulose nanofiber production has been studied. In order to study the effect of lignin on the effectiveness of nanofibrillation and its properties, the cellulose fiber was subjected to a bleaching process. Both types of fiber, bleached and unbleached, were subjected to two independent pretreatments, mechanical pretreatment and TEMPO-mediated oxidation, followed by high pressure homogenization treatment. The cellulose nanofibers obtained were widely characterized in terms of their chemical composition, morphology, thermal stability and crystallinity.

\section{Materials and Methods}

\subsection{Sample Preparation}

In this study, the raw material was obtained after the annual pruning of an olive tree plantation in the province of Córdoba (Spain), following olive harvest. The olive tree prunings were air-dried at room temperature until their moisture content was below $8 \%$ and stored until use. Before the raw 
material was subjected to the pulping process, it was chipped in an automatic grinder to obtain chips of $4-5 \mathrm{~cm}$ length to facilitate the fractioning of the lignocellulosic components.

\subsection{Pulping Process}

The olive chips were subjected to a pulping process in a $15 \mathrm{~L}$ capacity reactor, heated by an external heating jacket and rotated by means of a horizontal axis. The process carried out was a soda pulping process using $16 \% \mathrm{NaOH}$ (on dry matter) as a reaction agent, at $170{ }^{\circ} \mathrm{C}$ for $60 \mathrm{~min}$ and a liquid/solid ratio of 8:1. The conditions were selected according to previous studies and the experience of the research group for the production of cellulose pulp for paper production [31,32] After pulping, the treated chips were dispersed in a pulp disintegrator for $30 \mathrm{~min}$ at $1200 \mathrm{rpm}$. Once the chips were disintegrated, the fiber was passed through a Sprout-Bauer beater and separated by sieving through a netting of $0.14 \mathrm{~mm}$ mesh size. The cellulosic pulp was centrifuged to remove excess water and left to dry at room temperature until use. Afterwards, the unbleached pulp was subjected to a bleaching process. For this purpose, $0.3 \mathrm{~g}$ of sodium chlorite per gram of pulp was incubated in a $0.3 \%$ pulp suspension in water at $80^{\circ} \mathrm{C}$ for $3 \mathrm{~h}$. After cooling, the pulp was filtered and washed with acetone and several cycles of distilled water (Figure S1). This bleaching process allows the removal of practically all the lignin present in the fiber, maintaining the entire carbohydrate composition [33]. This makes it possible to study the effect of lignin on the production of cellulose nanofibers and their characteristics.

\subsection{Raw Material and Cellulosic Pulp Characterization}

The olive tree pruning biomass and the cellulosic pulp obtained were characterized in terms of the chemical composition of the lignocellulose matrix. Both were characterized according to their content of ethanol extractables, hot water extractables, ashes, lignin, hemicelluloses and $\alpha$-cellulose according to the TAPPI standards T-204, T-435, T-211, T-222, T-9m-54 and T-203 cm-09, respectively. The determination of each component of the chemical characterization was performed in triplicate and the means and standard deviations were calculated.

\subsection{Cellulose Nanofiber Production}

To obtain cellulose nanofibers (CNFs), two independent pretreatments were used, mechanical beating and TEMPO-mediated oxidation, both followed by a high-pressure homogenization treatment.

The mechanical pretreatment consisted of a mechanical refining (PFI beater) according to the ISO 5264-2:2002 standard, during 40,000 revolutions, to reach a Schopper-Riegler Degree ('SR) of 90 [26]. This pretreatment allows the fibrillation of the cellulose fibers by shear forces to facilitate nanofibrillation in the subsequent treatment. The TEMPO-mediated oxidation was carried out following the methodology described by Saito et al. [29]. The reaction was carried out at $\mathrm{pH} 10$ and started with the addition of a specific amount of $\mathrm{NaClO}$ solution in order to obtain an oxidative power of $5 \mathrm{mmol}$ per $\mathrm{g}$ of fiber. Once the addition of $\mathrm{NaClO}$ was complete, the $\mathrm{pH}$ was maintained by adding a $0.5 \mathrm{M} \mathrm{NaOH}$ solution. The reaction was finished when the $\mathrm{pH}$ remained stable.

A $1 \%$ pretreated fiber suspension was subjected to a nanofibrillation process in a high-pressure homogenizer (PandaPlus 2000, GEA Niro, Düsseldorf, Germany) in order to isolate the nanofibers that form the cellulose fibers. To avoid the occlusion of the homogenizer, gradual fibrillation was performed in the following sequence: 4 passes at 300 bars, 3 passes at 600 bars and 3 passes at 900 bars. This treatment has been demonstrated as an effective way of obtaining cellulose nanofibers from different raw materials and pretreatments [34].

By means of the mechanical and TEMPO-mediated oxidation pretreatments, CNFs were obtained, although in the case of unbleached pulp, residual lignin content remained in the final product (lignocellulose nanofibers; LCNF). 


\subsection{Cellulose Nanofiber Characterization}

In order to evaluate the suitability of the different pretreatments and the effect of the residual lignin in the final products, the CNFs/LCNFs obtained were deeply characterized. The nanofibrillation yield, which determines the nanometric fraction of the CNF suspension by the separation of the non-nanometric material by centrifugation, was determined according to the methodology described by Besbes et al. [35]. For this, a $0.1 \%$ cellulose nanofiber suspension was centrifuged at $11,000 \times g$ for $12 \mathrm{~min}$. The dry weight of the non-nanometric material precipitated during centrifugation compared to the dry weight of the initial suspension was used to inversely determine the nanofibrillation yield. The optical transmittance at $800 \mathrm{~nm}$ of the $0.1 \%$ cellulose nanofiber suspension was measured using a Lambda 25 UV-Spectrometer. The carboxyl content (CC) was determined using conductimetric titration as described by Besbes et al. [35]. The cationic demand (CD) was determined using a particle charge detector Mütek PCD 05 following the protocol described by Espinosa et al. [23]. The values of cationic demand and carboxyl content are used for the theoretical calculation of the specific surface area of the cellulose nanofibers assuming a simultaneous interaction between the hydroxyl and carboxyl groups of the cellulose nanofiber surface and PolyDADMAC in the monolayer coating [23]. Assuming the cylindrical geometry of the cellulose nanofiber and using the specific surface, it is possible to determine the width of the nanofibers. This method has been evaluated in previous publications, and the theoretical values are very good approximations to the values observed by electron microscopy [23].

\subsection{Viscosity, Degree of Polymerization and Length}

The intrinsic viscosity $\left(\eta_{s}\right)$ of the cellulose nanofibers was determined according to the ISO 5351:2010 standard. The degree of polymerization is related to the intrinsic viscosity (in $\mathrm{mL} \cdot \mathrm{g}^{-1}$ ) using the empirical relationship suggested by Marx-Figini [36]:

$$
\begin{gathered}
\mathrm{DP}(<950): \mathrm{DP}=\left(n_{\mathrm{s}} / 0.42\right) \\
\mathrm{DP}(>950): \mathrm{DP}^{0.76}=\left(n_{\mathrm{S}} / 2.28\right)
\end{gathered}
$$

The length of the cellulose nanofiber was estimated from the degree of polymerization values using the equation proposed by Shinoda et al. [37]:

$$
\text { Length }(\mathrm{nm})=4.286 \times \text { DP-757 }
$$

The measurements were made in triplicate, and the mean value and standard deviation were calculated.

\subsection{Fourier-Transform Infrared Spectroscopy (FTIR) Analysis}

The chemical structure of the cellulose nanofiber was analyzed by FTIR analysis. A FTIR-ATR Perkin-Elmer Spectrum Two was used to collect 20 infrared spectra in the range of 450-4000 $\mathrm{cm}^{-1}$ with a resolution of $4 \mathrm{~cm}^{-1}$. The analysis was performed on a CNF film prepared by hot-drying the cellulose nanofiber suspension.

\subsection{X-Ray Diffraction (XRD) Analysis}

The X-ray diffraction patterns of the cellulosic pulp and CNFs were obtained using a Bruker D8 Discover with a monochromatic source $\mathrm{CuK} \alpha 1$ with an angular range of $5^{\circ}-50^{\circ}$ at a $1.56^{\circ} / \mathrm{min}$ scan speed. The crystallinity index (CI) was calculated following the equation proposed by Segal et al. [38].

\subsection{Thermogravimetric Analysis (TGA)}

The thermal stability of the cellulosic fiber and cellulose nanofibers were measured using a Mettler Toledo Thermogravimetric analyzer (TGA/DSC 1). The measurements were performed by heating the 
samples $(10.0 \pm 1.0 \mathrm{mg})$ from room temperature to $600^{\circ} \mathrm{C}$ at a heating rate of $10^{\circ} \mathrm{C} / \mathrm{min}$ under a nitrogen atmosphere with a nitrogen gas flow of $50 \mathrm{~mL} \cdot \mathrm{min}^{-1}$. The temperature at which the degradation rate was at its maximum $\left(\mathrm{T}_{\max }\right)$ was evaluated analyzing the TGA equivalent derivate (DTG).

\section{Results and Discussion}

\subsection{Cellulosic Fiber Production and Characterization}

The chemical composition of the OTPB and the cellulosic pulp obtained is shown in Table 1. This composition is similar to that reported in previous work [39]. OTPB was subjected to a soda pulping process to facilitate the deconstruction of the cellulose fiber and the purification of the lignocellulosic components. The soda pulping process showed a yield of $32.0 \%$, similar to other more polluting processes such as kraft pulping (33\%) [40].

Table 1. Chemical composition of olive tree pruning biomass and cellulosic pulp.

\begin{tabular}{ccccccc}
\hline & Ext. EtOH (\%) & Ext. AQ (\%) & Ashes (\%) & Lignin (\%) & Hemicellulose (\%) & $\alpha$-Cellulose (\%) \\
\hline $\begin{array}{c}\text { Olive tree } \\
\text { pruning } \\
\text { biomass }\end{array}$ & $10.11 \pm 0.74$ & $6.2 \pm 0.46$ & $1.20 \pm 0.04$ & $21.80 \pm 1.10$ & $25.70 \pm 0.47$ & $41.41 \pm 0.76$ \\
\hline $\begin{array}{c}\text { Olive cellulosic } \\
\text { pulp }\end{array}$ & $1.18 \pm 0.02$ & $0.02 \pm 0.01$ & $2.20 \pm 0.01$ & $14.60 \pm 0.52$ & $25.68 \pm 0.08$ & $59.67 \pm 0.02$ \\
\hline
\end{tabular}

As can be observed, the non-structural elements (Ext. EtOH and Ext. AQ) were drastically reduced after the pulping process. In addition, the lignin content in the fiber was reduced to $14.6 \%$. On the other hand, the cellulosic fraction was purified and concentrated to almost $60 \%$ (similar to the value achieved by the kraft process) [40]. The hemicellulose content is a key parameter in the effectiveness of the nanofibrillation process. This component acts as a hydrated steric barrier to microfibril aggregation, preventing the re-agglomeration of the delaminated fiber. Chacker et al. [41] analyzed the role of hemicelluloses in the nanofibrillation process, determining that a hemicellulose content of about $25 \%$ in fiber is the ideal value to obtain the maximum efficiency in nanofibrillation. In pulps with a $12 \%$ of hemicellulose content, the fibrillation yield decreases by half in comparison with higher hemicellulose content pulps. The OTPB pulp obtained in this work retains most of the hemicelluloses present in the initial raw material, showing a content of $25.68 \%$, higher than that in the OTBP kraft pulp studied in previous work [37]. Compared to other cellulosic pulps successfully used in the production of cellulose nanofibers, OTPB showed a higher hemicellulose content than Eucalyptus kraft pulp (19.40\%), kraft pine pulp (14\%) and other agricultural residues such as corn $(20 \%)$, wheat $(23.30 \%)$, barley $(18.30 \%)$, oat $(16.40 \%)$, banana leaves $(20.28 \%)$, tomato $(11 \%)$ and lime residues $(10 \%)$, oil palm empty fruit bunches $(22 \%)$ and Brazilian satintail plants $(9 \%)[40,42-46]$. It is therefore concluded that the pulping process carried out produces cellulose pulp with an optimum chemical composition for the production of cellulose nanofibers.

The cellulosic pulp obtained was characterized in terms of thermal stability and crystallinity. Figure 1a shows the thermal degradation behavior of the OTBP cellulosic pulp. The OTBP pulp showed a multi-step degradation process by the presence of several components such as lignin, hemicellulose and cellulose that are degraded at different temperatures in the range studied. The initial weight loss step in the region of $30-120^{\circ} \mathrm{C}$ is associated with the evaporation of the absorbed and bound water in the fiber. The thermal degradation in the temperature range $120-350{ }^{\circ} \mathrm{C}$ is related to the breaking of glycosidic bonds, the pyrolysis of polysaccharides and the depolymerization of lignin, hemicellulose and cellulose. In the last region at $350-600{ }^{\circ} \mathrm{C}$, the weight loss is due to the pyrolysis of cellulose fibers and the remaining carbonaceous residue [47]. The DTG peak shows that the temperature of the maximum degradation $\left(\mathrm{T}_{\max }\right.$ ) of fiber is observed at $348^{\circ} \mathrm{C}$. Figure $1 \mathrm{~b}$ shows the $\mathrm{X}$-ray diffraction patterns of the fiber structure. It is possible to observe that it presents two major diffractions peaks at $2 \theta=16.1^{\circ}$ and $22.5^{\circ}$ corresponding to the 110 and 200 reflection planes of cellulose I's structure. 
The crystallinity index of the cellulosic fiber can be calculated by comparing the reflection intensity of the peak at $22.5^{\circ}$ (crystalline region) and the valley region between the two peaks associated with the amorphous region [38]. The CI observed for the OTPB pup was $60.26 \%$. Considering that the only lignocellulosic element that can present crystallinity is $\alpha$-cellulose, it is deduced that all of the cellulose present in the fiber $(59.67 \pm 0.02)$ shows a crystalline disposition, compared to the amorphous elements, hemicellulose and lignin, which do not provide crystallinity to the sample.

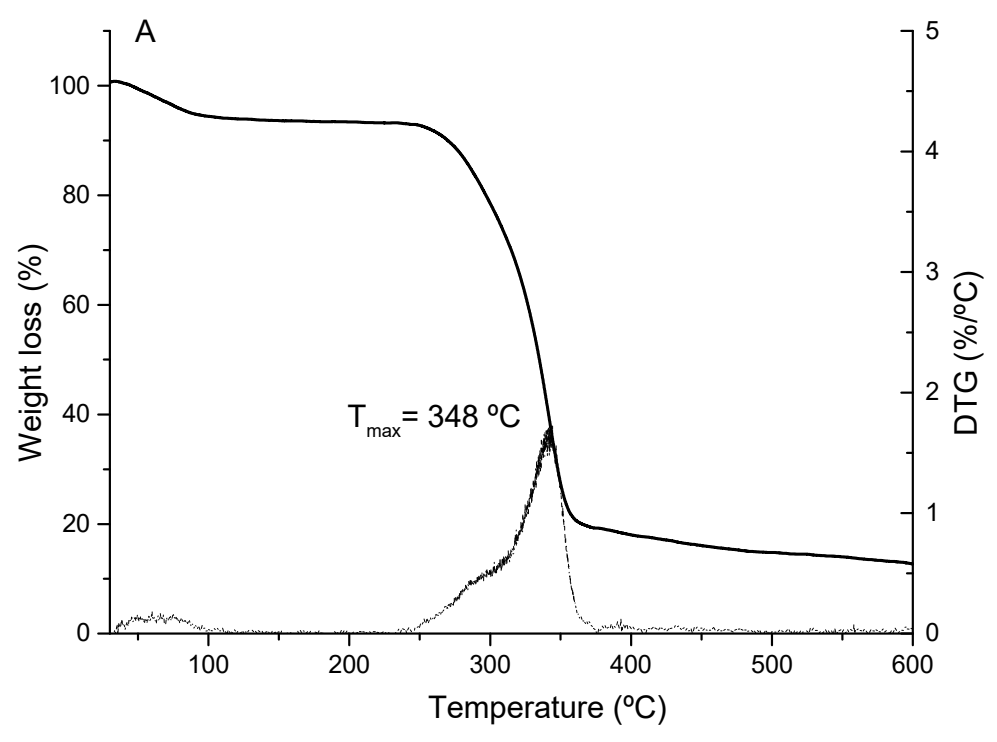

(a)

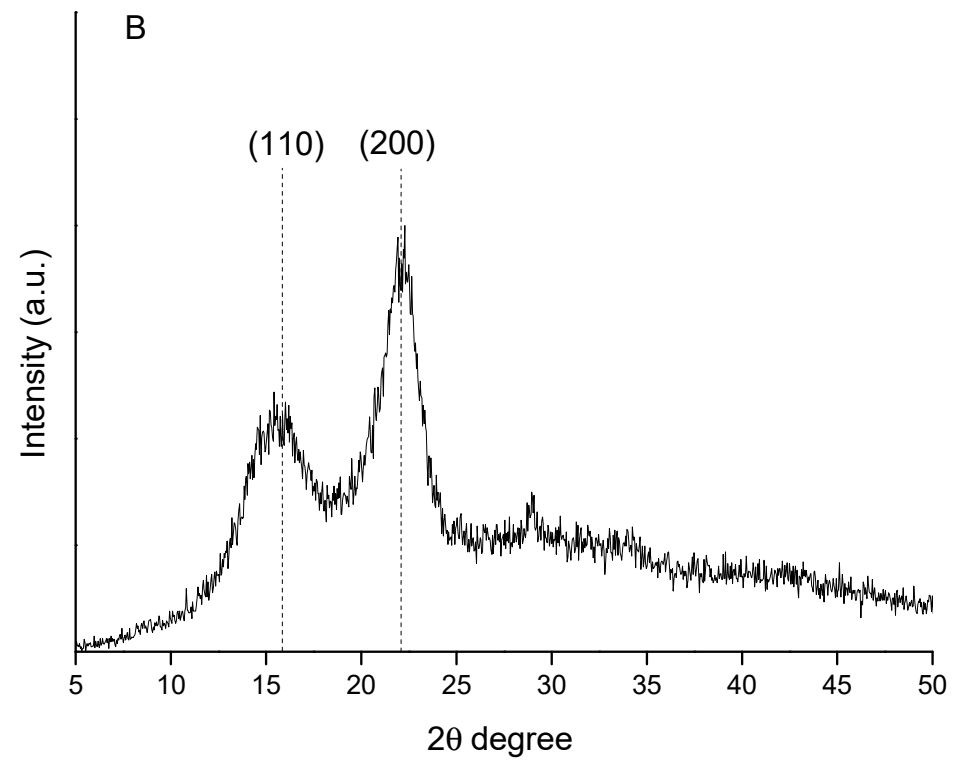

(b)

Figure 1. (a) Thermogravimetric analysis (TGA) and TGA equivalent derivate (DTG) curves and (b) the XRD pattern of OTBP pulp.

\subsection{Cellulose Nanofiber Isolation and Characterization}

The OTPB pulp was bleached to eliminate the lignin content while maintaining the carbohydrates in the fiber (hemicellulose and cellulose) and thus study the effect of lignin on the production of cellulose nanofibers through different pretreatments. Unbleached and bleached pulp were used for 
the production of lignocellulose nanofibers (LCNF) and cellulose nanofibers (CNF), respectively, through two different pretreatments, mechanical (Mec) and TEMPO-mediated oxidation (TO). The characterization of the different cellulose nanofibers in terms of nanofibrillation yield, transmittance, cationic demand, carboxyl content and morphology is shown in Table 2.

Table 2. Lignocellulose nanofiber and cellulose nanofiber characterization.

\begin{tabular}{lccccccc}
\hline Sample & $\boldsymbol{\eta} \mathbf{( \% )}$ & $\mathbf{T}_{\mathbf{8 0 0}} \mathbf{( \% )}$ & $\mathbf{C D}(\boldsymbol{\mu e q} / \mathbf{g})$ & $\mathbf{C C}(\boldsymbol{\mu m o l s} / \mathbf{g})$ & $\left.\boldsymbol{\sigma} \mathbf{( m}^{\mathbf{2}} / \mathbf{g}\right)$ & Width $(\mathbf{n m})$ & Length $(\mathbf{n m})$ \\
\hline LCNF-Mec & $15.33 \pm 0.47$ & 9.12 & $253.33 \pm 18.64$ & $150.72 \pm 15.17$ & 49.97 & 50 & 4671 \\
LCNF-TO & $17.98 \pm 0.89$ & 13.74 & $223.85 \pm 18.62$ & $152.43 \pm 6.63$ & 34.78 & 71 & 1478 \\
CNF-Mec & $13.34 \pm 0.02$ & 18.27 & $240.06 \pm 18.86$ & $147.83 \pm 3.63$ & 44.78 & 55 & 3331 \\
CNF-TO & $26.44 \pm 4.15$ & 50.59 & $521.27 \pm 9.33$ & $311.95 \pm 19.02$ & 101.93 & 24 & 705 \\
\hline
\end{tabular}

$\eta$ : nanofibrillation yield; $\mathrm{T}_{800}$ : optical transmittance; CD: cationic demand; CC: carboxyl content; $\sigma$ : specific surface area.

The nanofibrillation yield ( $n$ ) for the LCNF and CNF ranges from $13.34 \%$ to $26.44 \%$. These low yields in comparison with those for cellulose nanofibers obtained by enzymatic hydrolysis or the TEMPO-mediated oxidation of CNF from fully bleached wood pulp show that the obtained suspension is composed of cellulose nanofibers with large widths and cellulose microfibers $[48,49]$. The optical transmittance (T800) of the cellulose nanofiber suspension is an indirect indicator of the nanofibrillation yield. The cellulose microfibers contained in the suspension produce a higher light scattering compared to the nanofibers, so this parameter is highly related to yield and nanometric width. As with nanofibrillation yield, only slight differences in T800 are observed between the various nanofibers, except for CNF-TO. Since the chemical compositions of LCNF and CNF are different, the transmittance of the suspensions should not be considered as a key parameter in the characterization of the suspensions since lignin affects the refractive index. It is observed that CNF-TO presents a higher transmittance due to the fact that it presents a significantly higher nanofibrillation yield than the rest of nanofibers, and in addition, it does not contain lignin in its composition.

Cationic demand (CD) refers to the ability of the anionic surface of nanofibers to capture and interact with cationic substances. This value is highly related to the specific surface of the nanofiber; the larger the surface, the greater the capacity for interaction and the carboxyl content on that surface. The values of both parameters for LCNF-Mec, LCNF-TO and CNF-Mec are similar or even higher than what has been reported in the literature for CNF obtained by mechanical pretreatment or TEMPO-mediated oxidation from fibers with high lignin content [34,50-53]. It is observed again that there are not great differences in the cationic demand and carboxyl content, except for CNF-TO. In CNF-TO, TEMPO-mediated oxidation is much more effective that when it is performed on LCNF, as revealed by the increase in carboxyl content. It is observed that CNF-TO increases the carboxyl content by more than double compared to CNF-Mec. This increase is produced by the conversion of hydroxyl groups at the $\mathrm{C} 6$ positions on the surface of the cellulose fibers into carboxyl groups, enabling the delamination of the fiber by the electrostatic repulsion of the charged fiber surface [54]. On the other hand, in the case of LCNF, differences between both pretreatments are negligible. The presence of lignin in the fiber can affect the effectiveness of the oxidation reaction because the reaction activator, $\mathrm{NaClO}$, is also consumed as the bleaching agent, producing the oxidation and dissolution of the lignin, thus preventing the selective activation of the catalyst. In fibers previously reported in literature with a lignin content lower than $10 \%$, a partial oxidation of the $-\mathrm{OH}$ groups of the cellulose is produced, reaching maximum values of $300 \mu \mathrm{mol} / \mathrm{g}$, higher than those reached for LCNF-TO described in this work $(152.34 \mu \mathrm{mols} / \mathrm{g})$, but not as high as those obtained for bleached wood pulps that can reach 1000 $\mu \mathrm{mol} / \mathrm{g}[34,49,52]$.

The specific surface values, again, show differences in CNF-TO, which shows a considerably higher result than the other cellulose nanofibers. This is a very important parameter when using cellulose nanofibers as a reinforcing agent in materials produced from lignocellulosic materials such as paper, cardboard or fiberboards [12,55]. A larger specific surface area allows for a higher bonding 
capacity with adjacent fibers, thus improving the mechanical properties of the final product. Cellulose nanofibers with similar specific surface areas produce an increase about $100 \%$ in the mechanical properties of paper and carboard with low amounts of LCNF addition (3\%) [53].

Nanofiber width, despite being within the nanometric range $(24-71 \mathrm{~nm})$, presents some differences that are discussed. For mechanical pretreatment, the presence of lignin in the fiber (LCNF-Mec) produces greater fibrillation in the fiber, producing a smaller width than CNF-Mec. This could be due to the lignin antioxidant action that prevents the re-bonding of the covalent bonds broken during the mechanical treatments [56]. Regarding TEMPO-mediated oxidation, differences are shown with the presence of lignin, being adverse because of the effect explained above. The length of nanofibers is an important parameter when analyzing the suitability of the application of cellulose nanofibers. The lignin content can affect the effectiveness of the method used for length determination through intrinsic viscosity. However, this method allows an estimation of the effect of the different pretreatments on the length parameter. In a generalized way, decreases in the lengths were observed when the fiber was subjected to TEMPO-mediated oxidation of $68.4 \%$ and $78.8 \%$ for LCNF-TO and CNF-TO, respectively, with respect to those following mechanical pretreatment. It is caused by the degradation of the cellulose amorphous regions into gluconic acid or cellulose-derived small fragments by depolymerization and $\beta$-elimination [57]. The length of the nanofibers is strongly related to the mechanical properties of the final composites made of cellulose nanofibers. It is therefore necessary to achieve a balance between the nanometric size reached during the nanofibrillation process and the shortening of the fiber due to its degradation. The aspect ratio $(\mathrm{L} / \mathrm{D})$ is a parameter that shows the relationship between length and width. It is observed that the different cellulose nanofibers showed aspect ratios of 93.44, 20.82, 60.56 and 29.38 for LCNF-Mec, LCNF-TO, CNF-Mec and CNF-TO, respectively. It is shown that although the mechanically pretreated nanofibers present a higher width than CNF-TO, they had a higher aspect ratio due to the low degradation that they underwent in the production process. Therefore, even though CNF-TO has a larger specific surface area and is thus more suitable for application in products made from lignocellulosic material (paper, cardboard, etc.), LCNF-Mec and CNF-Mec would show better behavior when added as a reinforcing agent on polymeric matrices [58].

The chemical composition of the different cellulose nanofibers was analyzed by a FTIR technique (Figure 2). All analyzed samples, as expected, show a spectrum typical of lignocellulosic materials. The peaks at 3300 and $2900 \mathrm{~cm}^{-1}$ are associated with the stretching vibration of the $\mathrm{OH}$ and $\mathrm{CH}$ groups present in the cellulose chains. The peaks in the range of $1350-1250 \mathrm{~cm}^{-1}$ are attributed to the presence of chemical groups of the hemicelluloses. The peaks at 1190, 1070 and $890 \mathrm{~cm}^{-1}$ are associated with the stretching and rocking vibrations of the $\mathrm{C}-\mathrm{O}, \mathrm{C}-\mathrm{H}$ and $\mathrm{CH}_{2}$ groups of cellulose [52]. However, there are some differences between the various cellulose nanofibers. It is observed that cellulose nanofibers obtained from OTPB bleached pulp (CNF-Mec and CNF-TO) do not show the peak at $1510 \mathrm{~cm}^{-1}$ that is observed in lignocellulose nanofibers (LCNF). This peak is related to the $\mathrm{C}=\mathrm{C}$ symmetrical stretching of the aromatic rings, characteristic of the lignin. As expected, due to the nearly total elimination of lignin content in the bleached pulp, this peak is not observed in CNF. Another difference is observed in the peak at $1610 \mathrm{~cm}^{-1}$, corresponding to the $\mathrm{C}=\mathrm{O}$ stretching vibration in carboxyl groups. An important increase in the intensity of the peak is observed in the CNF-TO due to the regioselective conversion of C6 primary hydroxyl groups to carboxyl groups by the TEMPO-mediated oxidation.

The effects of the different pretreatments on the crystallinity of the cellulose nanofibers are shown in Figure 3. It is observed that the same peaks related to the 110 and 200 reflection planes of cellulose I are observed again, implying that the crystalline structure of the original fiber is maintained. The crystallinity index (CI) was calculated in the same way as for OTPB pulp. It shows that cellulose nanofibers present a lower CI $(24 \%-49 \%)$ than the original fiber $(60.26 \%)$. With regards to nanofibers obtained by mechanical pretreatment, they are produced by the disordering of the crystalline regions of the cellulose chain by the shear forces produced in the high-pressure homogenization process and during mechanical pretreatment. For TEMPO-mediated oxidized nanofibers, they are produced by the conversion of ordered cellulose structures into disordered structures by the sodium glucuronosyl 
units during the oxidation reaction [59]. CNF is observed to have a greater crystallinity than LCNF. This is due to the lignin elimination during the bleaching process and the consequent elimination of the amorphous component of the lignocellulose matrix, increasing the total crystallinity of the fiber. In addition, it is observed that mechanical pretreatment produced a greater disordering in the cellulose chain than the TEMPO-mediated oxidation.

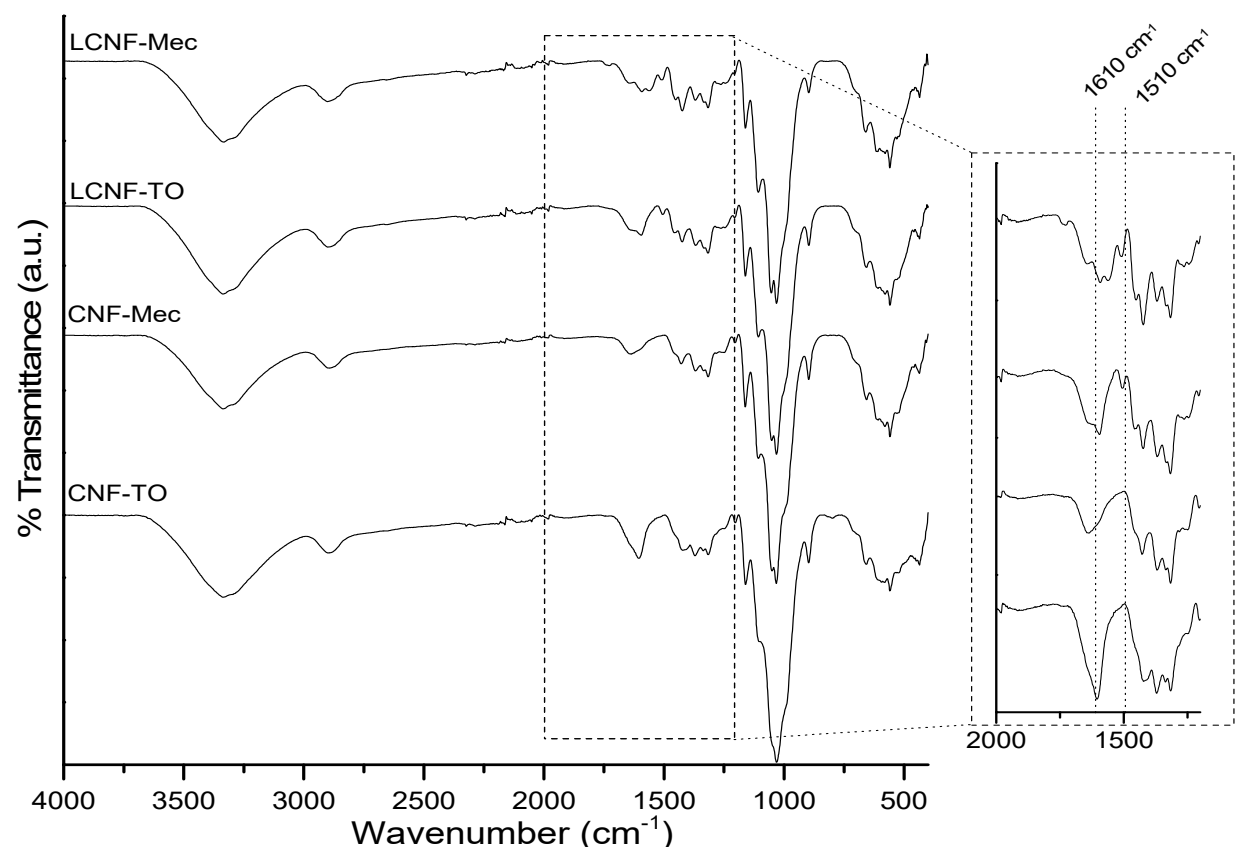

Figure 2. FTIR spectra of the different cellulose nanofibers.

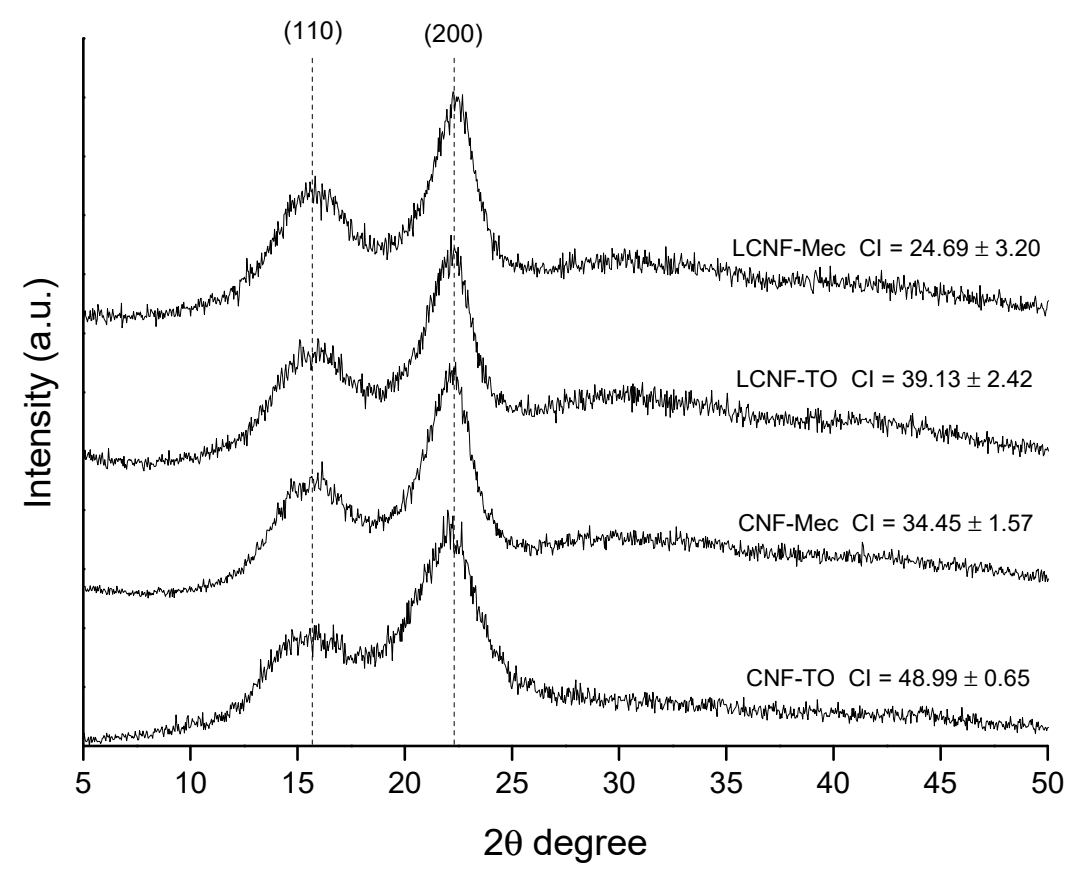

Figure 3. XRD diffraction patterns and crystallinity indices of the cellulose nanofibers. 
The thermal stability of the different cellulose nanofibers was studied through the analysis of the TGA and DTG curves (Figure 4). The thermal degradation behavior shows three degradation stages observed in the initial fiber: (i) moisture loss, (ii) glycosidic bond degradation and (iii) cellulose pyrolysis. It is observed that LCNF (Figure 4a) and CNF (Figure $4 \mathrm{~b}$ ) present lower values for maximum thermal degradation, i.e., a lower $\mathrm{T}_{\max }$, than that obtained for OTPB pulp $\left(348^{\circ} \mathrm{C}\right)$. This is due to the larger specific surface of the nanometric-size fibers, which means that they are more exposed to heat, and degradation occurs more quickly than in the original fiber. It can be seen that for cellulose nanofibers obtained by mechanical pretreatment, there are no differences according to the presence or absence of lignin, both showing a $\mathrm{T}_{\max }=343^{\circ} \mathrm{C}$. However, analyzing the total mass loss, it is observed that a residual mass at $600{ }^{\circ} \mathrm{C}$ of $15.14 \%$ remains for LCNF-Mec compared to $8.95 \%$ for the CNF-Mec. This fact is not indicative of a higher thermal stability, but it indicates that a greater carbonaceous residue is produced after the pyrolysis of the lignocellulosic components due to the aromatic structure of lignin. Regarding the cellulose nanofibers obtained by TEMPO-mediated oxidation, noticeable differences are observed, showing maximum degradations at $325^{\circ} \mathrm{C}$ and $298^{\circ} \mathrm{C}$ for LCNF-TO and CNF-TO, respectively. CNF-TO presents worse thermal stability than LCNF-TO and the products obtained by mechanical pretreatment, since in addition to the nanometric size, it has a greater number of free ends (higher cationic demand and carboxyl content), which favors thermal degradation [60]. In addition, contrarily to what has been observed in the nanofibers obtained by mechanical pretreatment, a large increase in the residual mass was produced in CNF-TO $(29.76 \%)$ in comparison with the values obtained for LCNF-TO $(16.54 \%)$. This fact is produced by the introduction of carboxyl groups on the surface of the fiber during TEMPO-mediated oxidation, increasing the carboxyl content, especially for CNF-TO $(311.95 \mu \mathrm{mol} / \mathrm{g})$ as observed through its characterization. It is therefore concluded that CNF-Mec and LCNF-Mec, in addition to presenting higher aspect ratios that can result in greater reinforcement effects in polymeric matrices, can be used in polymers with higher transition temperatures compared to CNF-TO and LCNF-TO due to their greater thermal stability.

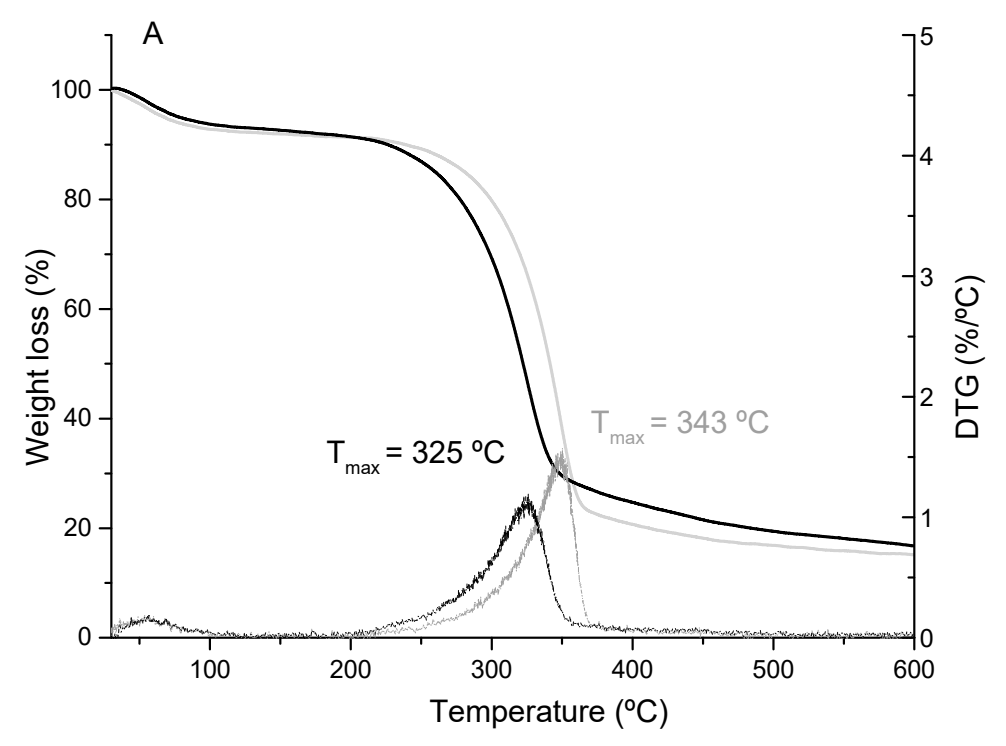

(a)

Figure 4. Cont. 


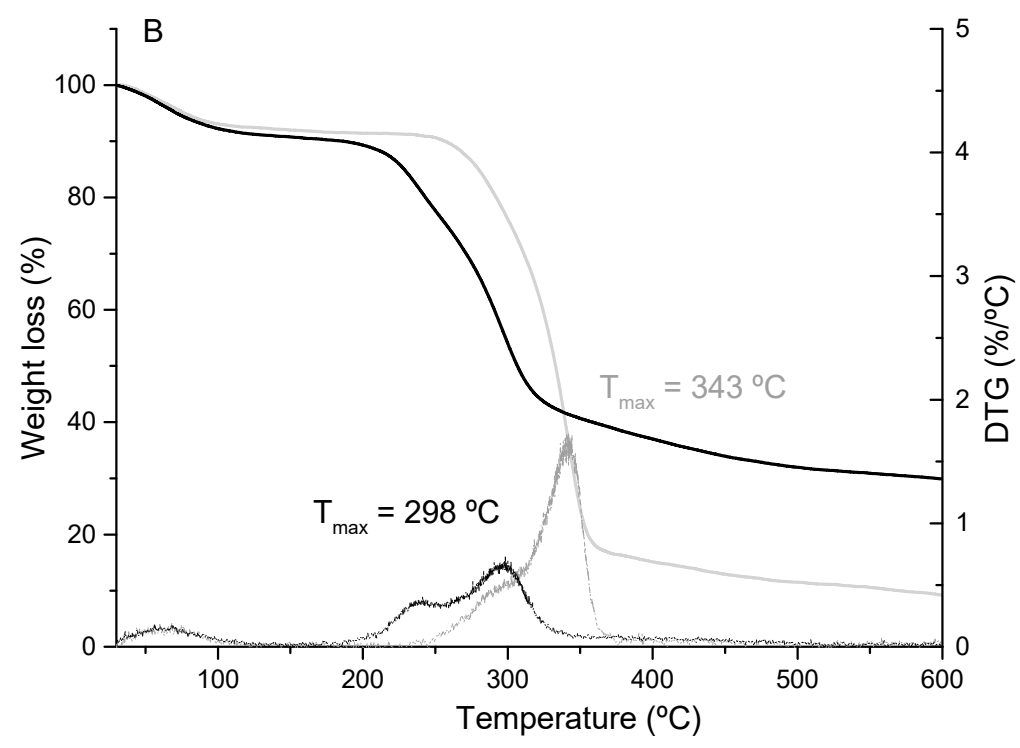

(b)

Figure 4. TGA and DTG curves for the different cellulose nanofibers: (a) lignocellulose nanofibers (LCNF) and (b) cellulose nanofibers (CNF). Black curves for those obtained by TEMPO-mediated oxidation and grey from mechanical pretreatment.

\section{Conclusions}

Olive tree pruning biomass (OTPB) was identified as a lignocellulosic source for the production of cellulose nanofibers from cellulosic pulps obtained by a sustainable pulping process. The cellulose nanofibers were produced by two different pretreatments, mechanical and TEMPO-mediated oxidation, followed by high-pressure homogenization. The influence of the residual lignin content on the effectiveness of the different pretreatments was analyzed by the thorough characterization of the cellulose nanofibers produced. All the cellulose nanofibers produced in this work were in the nanometric range; however, important differences were observed. TEMPO-mediated oxidation is more effective with bleached pulp; however, mechanical pretreatment was favored by the presence of lignin. The presence of lignin results in cellulose nanofibers with low crystallinity indices following mechanical pretreatment and TEMPO-mediated oxidation (24.69\% and 39.13\%) in comparison with those produced from bleached nanofibers $(39.13 \%$ and $48.99 \%)$. The thermal stability of the cellulose nanofibers produced by mechanical treatment shows similar values regardless of the presence of lignin $\left(343^{\circ} \mathrm{C}\right)$; however, in the TEMPO-mediated oxidation, the lignin content produces a greater thermal stability $\left(325^{\circ} \mathrm{C}\right)$ in comparison with that obtained with bleached nanofibers $\left(298^{\circ} \mathrm{C}\right)$. The characteristics of the cellulose nanofibers obtained are of great interest for their application in different sectors.

Supplementary Materials: The following are available online at http://www.mdpi.com/2073-4395/10/5/696/s1, Figure S1: Cellulose pulp images.

Author Contributions: The article was conceptualized by A.R. and F.P.-R. The experimental work was realized by M.S.-G., I.B.-V. and E.C. The article was written by E.E. The article was reviewer by A.R. All authors have read and agreed to the published version of the manuscript.

Funding: The authors are grateful to Spain's DGICyT, MICINN for funding this research within the framework of the Project CTQ2016-78729-R.

Acknowledgments: The authors wish to acknowledge the support of the Central Service for Research Support (SCAI) at the university of Córdoba.

Conflicts of Interest: The authors declare no conflict of interest 


\section{References}

1. Gurría, P.; Ronzon, T.; Tamosiunas, S.; López, R.; García Condado, S.; Guillén, J.; Cazzaniga, N.E.; Jonsson, R.; Banja, M.; Fiore, G.; et al. Biomass Flows in the European Union; Publications Office of the European Union: Luxembourg, Luxembourg, 2017.

2. Food and Agriculture Organization of the United Nations (FAO). 2018 FAOSTAT. Available online: http: //www.fao.org/faostat/en/\#data (accessed on 2 April 2020).

3. Miranda, I.; Simões, R.; Medeiros, B.; Nampoothiri, K.M.; Sukumaran, R.K.; Rajan, D.; Pereira, H.; Ferreira-Dias, S. Valorization of lignocellulosic residues from the olive oil industry by production of lignin, glucose and functional sugars. Bioresource Technol. 2019, 292, 121936. [CrossRef] [PubMed]

4. Fernandes-Klajn, F.; Romero-García, J.M.; Díaz, M.J.; Castro, E. Comparison of fermentation strategies for ethanol production from olive tree pruning biomass. Ind. Crop. Prod. 2018, 122, 98-106. [CrossRef]

5. Santos, J.I.; Fillat, Ú.; Martín-Sampedro, R.; Eugenio, M.E.; Negro, M.J.; Ballesteros, I.; Rodríguez, A.; Ibarra, D. Evaluation of lignins from side-streams generated in an olive tree pruning-based biorefinery: Bioethanol production and alkaline pulping. Int. J. Biol. Macromol. 2017, 105, 238-251. [CrossRef]

6. Suardi, A.; Latterini, F.; Alfano, V.; Palmieri, N.; Bergonzoli, S.; Pari, L. Analysis of the Work Productivity and Costs of a Stationary Chipper Applied to the Harvesting of Olive Tree Pruning for Bio-Energy Production. Energies 2020, 13, 1359. [CrossRef]

7. Liuzzi, S.; Rubino, C.; Martellotta, F.; Stefanizzi, P.; Casavola, C.; Pappalettera, G. Characterization of biomass-based materials for building applications: The case of straw and olive tree waste. Ind. Crop. Prod. 2020, 147, 112229. [CrossRef]

8. Mutjé, P.; Pèlach, M.A.; Vilaseca, F.; García, J.C.; Jiménez, L. A comparative study of the effect of refining on organosolv pulp from olive trimmings and kraft pulp from eucalyptus wood. Bioresource Technol. 2005, 96, 1125-1129. [CrossRef]

9. García, A.; Gandini, A.; Labidi, J.; Belgacem, N.; Bras, J. Industrial and crop wastes: A new source for nanocellulose biorefinery. Ind. Crop. Prod. 2016, 93, 26-38. [CrossRef]

10. Balea, A.; Fuente, E.; Monte, C.M.; Merayo, N.; Campano, C.; Negro, C.; Blanco, A. Industrial Application of Nanocelluloses in Papermaking: A Review of Challenges, Technical Solutions, and Market Perspectives. Molecules 2020, 25, 526. [CrossRef]

11. Inshakova, E.; Inshakov, O. World market for nanomaterials: Structure and trends. MATEC Web Conf. 2017, 129, 02013. [CrossRef]

12. Boufi, S.; González, I.; Delgado-Aguilar, M.; Tarrès, Q.; Pèlach, M.À.; Mutjé, P. Nanofibrillated cellulose as an additive in papermaking process: A review. Carbohyd. Polym. 2016, 154, 151-166. [CrossRef]

13. Tayeb, P.H.; Tayeb, A. Nanocellulose applications in sustainable electrochemical and piezoelectric systems: A review. Carbohyd. Polym. 2019, 224, 115149. [CrossRef] [PubMed]

14. Hsu, H.H.; Zhong, W. Nanocellulose-Based Conductive Membranes for Free-Standing Supercapacitors: A Review. Membranes 2019, 9, 74. [CrossRef] [PubMed]

15. Bongao, H.C.; Gabatino, R.R.A.; Arias, C.F.H.; Magdaluyo, E.R. Micro/nanocellulose from waste Pili (Canarium ovatum) pulp as a potential anti-ageing ingredient for cosmetic formulations. Mater. Today-Proc. 2020, 22, 275-280. [CrossRef]

16. Klemm, D.; Cranston, E.D.; Fischer, D.; Gama, M.; Kedzior, S.A.; Kralisch, D.; Kramer, F.; Kondo, T.; Lindström, T.; Nietzsche, S.; et al. Nanocellulose as a natural source for groundbreaking applications in materials science: Today's state. Mater. Today 2018, 21, 720-748. [CrossRef]

17. Putro, J.N.; Kurniawan, A.; Ismadji, S.; Ju, Y.-H. Nanocellulose based biosorbents for wastewater treatment: Study of isotherm, kinetic, thermodynamic and reusability. Environ. Nanotechnol. Monit. Manage. 2017, 8, 134-149. [CrossRef]

18. Zhang, C.; Feng, X.; Wang, B.; Mao, Z.; Xu, H.; Zhong, Y.; Zhang, L.; Chen, X.; Sui, X. Nanocellulose sponges as efficient continuous flow reactors. Carbohyd. Polym. 2019, 224, 115184. [CrossRef]

19. Barnat-Hunek, D.; Grzegorczyk-Frańczak, M.; Szymańska-Chargot, M.; Łagód, G. Effect of Eco-Friendly Cellulose Nanocrystals on Physical Properties of Cement Mortars. Polymers 2019, 11, 2088. [CrossRef]

20. Liu, Y.; Sui, Y.; Liu, C.; Liu, C.; Wu, M.; Li, B.; Li, Y. A physically crosslinked polydopamine/nanocellulose hydrogel as potential versatile vehicles for drug delivery and wound healing. Carbohyd. Polym. 2018, 188, 27-36. [CrossRef] 
21. Moohan, J.; Stewart, A.S.; Espinosa, E.; Rosal, A.; Rodríguez, A.; Larrañeta, E.; Donnelly, F.R.; Domínguez-Robles, J. Cellulose Nanofibers and Other Biopolymers for Biomedical Applications. A Review. Appl. Sci. 2019, 10, 65. [CrossRef]

22. Dufresne, A. Nanocellulose, from Nature to High Performance Tailored Materials; Walter de Gruyter GmbH.: Berlin, Germany, 2012.

23. Espinosa, E.; Tarres, Q.; Delgado-Aguilar, M.; Gonzalez, I.; Mutje, P.; Rodriguez, A. Suitability of wheat straw semichemical pulp for the fabrication of lignocellulosic nanofibres and their application to papermaking slurries. Cellulose 2016, 23, 837-852. [CrossRef]

24. Rol, F.; Karakashov, B.; Nechyporchuk, O.; Terrien, M.; Meyer, V.; Dufresne, A.; Belgacem, M.N.; Bras, J. Pilot-Scale Twin Screw Extrusion and Chemical Pretreatment as an Energy-Efficient Method for the Production of Nanofibrillated Cellulose at High Solid Content. ACS Sustain. Chem. Eng. 2017, 5, 6524-6531. [CrossRef]

25. Wang, W.; Mozuch, M.D.; Sabo, R.C.; Kersten, P.; Zhu, J.Y.; Jin, Y. Production of cellulose nanofibrils from bleached eucalyptus fibers by hyperthermostable endoglucanase treatment and subsequent microfluidization. Cellulose 2015, 22, 351-361. [CrossRef]

26. Espinosa, E.; Rol, F.; Bras, J.; Rodríguez, A. Production of lignocellulose nanofibers from wheat straw by different fibrillation methods. Comparison of its viability in cardboard recycling process. J. Clean. Prod. 2019, 239, 118083. [CrossRef]

27. Espinosa, E.; Dominguez-Robles, J.; Sanchez, R.; Tarres, Q.; Rodriguez, A. The effect of pre-treatment on the production of lignocellulosic nanofibers and their application as a reinforcing agent in paper. Cellulose 2017, 24, 2605-2618. [CrossRef]

28. Tarres, Q.; Saguer, E.; Pelach, M.A.; Alcala, M.; Delgado-Aguilar, M.; Mutje, P. The feasibility of incorporating cellulose micro/nanofibers in papermaking processes: The relevance of enzymatic hydrolysis. Cellulose 2016, 23, 1433-1445. [CrossRef]

29. Saito, T.; Kimura, S.; Nishiyama, Y.; Isogai, A. Cellulose Nanofibers Prepared by TEMPO-Mediated Oxidation of Native Cellulose. Biomacromolecules 2007, 8, 2485-2491. [CrossRef]

30. Rol, F.; Saini, S.; Meyer, V.; Petit-Conil, M.; Bras, J. Production of cationic nanofibrils of cellulose by twin-screw extrusion. Ind. Crop. Prod. 2019, 137, 81-88. [CrossRef]

31. Jiménez, L.; Pérez, I.; de la Torre, J.; García, J.C. The effect of processing variables on the soda pulping of olive tree wood. Bioresource Technol. 1999, 69, 95-102. [CrossRef]

32. Martin-Sampedro, R.; Rodríguez, A.; Requejo, A.; Eugenio, M.E. Improvement of TCF bleaching of olive tree pruning residue pulp by addition of a laccase and/or xylanase pre-treatment. Bioresources 2012, 7, 1488-1505. [CrossRef]

33. Espinosa, E.; Bascón-Villegas, I.; Rosal, A.; Pérez-Rodríguez, F.; Chinga-Carrasco, G.; Rodríguez, A. PVA/(ligno)nanocellulose biocomposite films. Effect of residual lingin content on the structural, mechanical, barrier and antioxidant properties. Int. J. Biol. Macromol. 2019, 141, 197-206. [CrossRef]

34. Espinosa, E.; Sánchez, R.; González, Z.; Domínguez-Robles, J.; Ferrari, B.; Rodríguez, A. Rapidly growing vegetables as new sources for lignocellulose nanofibre isolation: Physicochemical, thermal and rheological characterisation. Carbohyd. Polym. 2017, 175, 27-37. [CrossRef] [PubMed]

35. Besbes, I.; Alila, S.; Boufi, S. Nanofibrillated cellulose from TEMPO-oxidized eucalyptus fibres: Effect of the carboxyl content. Carbohyd. Polym. 2011, 84, 975-983. [CrossRef]

36. Marx-Figini, M. The acid-catalyzed degradation of cellulose linters in distinct ranges of degree of polymerization. J. Appl. Polym. Sci. 1987, 33, 2097-2105. [CrossRef]

37. Shinoda, R.; Saito, T.; Okita, Y.; Isogai, A. Relationship between Length and Degree of Polymerization of TEMPO-Oxidized Cellulose Nanofibrils. Biomacromolecules 2012, 13, 842-849. [CrossRef] [PubMed]

38. Segal, L.; Creely, J.J.; Martin, A.E.; Conrad, C.M. An empirical method for estimating the degree of crystallintiy of native cellulose using X-ray diffractometer. Text. Res. J. 1959, 29, 786-974. [CrossRef]

39. Requejo, A.; Rodríguez, A.; Colodette, J.L.; Gomide, J.L.; Jiménez, L. Optimization of ECF bleaching and refining of kraft pulping from olive tree pruning. BioResources 2012, 7, 4046-4055.

40. Fillat, Ú.; Wicklein, B.; Martín-Sampedro, R.; Ibarra, D.; Ruiz-Hitzky, E.; Valencia, C.; Sarrión, A.; Castro, E.; Eugenio, M.E. Assessing cellulose nanofiber production from olive tree pruning residue. Carbohyd. Polym. 2018, 179, 252-261. [CrossRef]

41. Chaker, A.; Alila, S.; Mutje, P.; Vilar, M.R.; Boufi, S. Key role of the hemicellulose content and the cell morphology on the nanofibrillation effectiveness of cellulose pulps. Cellulose 2013, 20, 2863-2875. [CrossRef] 
42. Rajan, K.; Djioleu, A.; Kandhola, G.; Labbé, N.; Sakon, J.; Carrier, D.J.; Kim, J.-W. Investigating the effects of hemicellulose pre-extraction on the production and characterization of loblolly pine nanocellulose. Cellulose 2020. [CrossRef]

43. Kassab, Z.; Kassem, I.; Hannache, H.; Bouhfid, R.; Qaiss, A.E.K.; El Achaby, M. Tomato plant residue as new renewable source for cellulose production: Extraction of cellulose nanocrystals with different surface functionalities. Cellulose 2020. [CrossRef]

44. Jongaroontaprangsee, S.; Chiewchan, N.; Devahastin, S. Production of nanocellulose from lime residues using chemical-free technology. Mater. Today-Proc. 2018, 5, 11095-11100. [CrossRef]

45. Septevani, A.A.; Rifathin, A.; Sari, A.A.; Sampora, Y.; Ariani, G.N.; Sudiyarmanto; Sondari, D. Oil palm empty fruit bunch-based nanocellulose as a super-adsorbent for water remediation. Carbohyd. Polym. 2020, 229, 115433. [CrossRef] [PubMed]

46. Benini, K.C.C.d.C.; Voorwald, H.J.C.; Cioffi, M.O.H.; Rezende, M.C.; Arantes, V. Preparation of nanocellulose from Imperata brasiliensis grass using Taguchi method. Carbohyd. Polym. 2018, 192, 337-346. [CrossRef] [PubMed]

47. Alemdar, A.; Sain, M. Isolation and characterization of nanofibers from agricultural residues - Wheat straw and soy hulls. Bioresource Technol. 2008, 99, 1664-1671. [CrossRef]

48. Delgado-Aguilar, M.; González Tovar, I.; Tarrés, Q.; Alcalá, M.; Pèlach, M.À.; Mutjé, P. Approaching a Low-Cost Production of Cellulose Nanofibers for Papermaking Applications. BioResources 2015, 10, 5435-5455. [CrossRef]

49. González, I.; Boufi, S.; Pèlach, M.A.; Alcalà, M.; Vilaseca, F.; Mutjé, P. Nanofibrillated cellulose as papper additive in eucalyptus pulp. BioResources 2012, 7, 5167-5180. [CrossRef]

50. Vallejos, M.E.; Felissia, F.E.; Area, M.C.; Ehman, N.V.; Tarrés, Q.; Mutjé, P. Nanofibrillated cellulose (CNF) from eucalyptus sawdust as a dry strength agent of unrefined eucalyptus handsheets. Carbohyd. Polym. 2016, 139, 99-105. [CrossRef]

51. Tarrés, Q.; Ehman, N.V.; Vallejos, M.E.; Area, M.C.; Delgado-Aguilar, M.; Mutjé, P. Lignocellulosic nanofibers from triticale straw: The influence of hemicelluloses and lignin in their production and properties. Carbohyd. Polym. 2017, 163, 20-27. [CrossRef]

52. Espinosa, E.; Sánchez, R.; Otero, R.; Domínguez-Robles, J.; Rodríguez, A. A comparative study of the suitability of different cereal straws for lignocellulose nanofibers isolation. Int. J. Biol. Macromol. 2017, 103, 990-999. [CrossRef]

53. Tarrés, Q.; Espinosa, E.; Domínguez-Robles, J.; Rodríguez, A.; Mutjé, P.; Delgado-Aguilar, M. The suitability of banana leaf residue as raw material for the production of high lignin content micro/nano fibers: From residue to value-added products. Ind. Crop. Prod. 2017, 99, 27-33. [CrossRef]

54. Saito, T.; Shibata, I.; Isogai, A.; Suguri, N.; Sumikawa, N. Distribution of carboxylate groups introduced into cotton linters by the TEMPO-mediated oxidation. Carbohyd. Polym. 2005, 61, 414-419. [CrossRef]

55. Theng, D.; Arbat, G.; Delgado-Aguilar, M.; Vilaseca, F.; Ngo, B.; Mutjé, P. All-lignocellulosic fiberboard from corn biomass and cellulose nanofibers. Ind. Crop. Prod. 2015, 76, 166-173. [CrossRef]

56. Solala, I.; Iglesias, M.C.; Peresin, M.S. On the potential of lignin-containing cellulose nanofibrils (LCNFs): A review on properties and applications. Cellulose 2019. [CrossRef]

57. Sang, X.K.; Qin, C.R.; Tong, Z.F.; Kong, S.; Jia, Z.; Wan, G.C.; Liu, X.L. Mechanism and kinetics studies of carboxyl group formation on the surface of cellulose fiber in a TEMPO-mediated system. Cellulose 2017, 24, 2415-2425. [CrossRef]

58. Zimmermann, T.; Bordeanu, N.; Strub, E. Properties of nanofibrillated cellulose from different raw materials and its reinforcement potential. Carbohyd. Polym. 2010, 79, 1086-1093. [CrossRef]

59. Puangsin, B.; Yang, Q.L.; Saito, T.; Isogai, A. Comparative characterization of TEMPO-oxidized cellulose nanofibril films prepared from non-wood resources. Int. J. Biol. Macromol. 2013, 59, 208-213. [CrossRef]

60. Sharma, P.R.; Varma, A.J. Thermal stability of cellulose and their nanoparticles: Effect of incremental increases in carboxyl and aldehyde groups. Carbohyd. Polym. 2014, 114, 339-343. [CrossRef]

(C) 2020 by the authors. Licensee MDPI, Basel, Switzerland. This article is an open access article distributed under the terms and conditions of the Creative Commons Attribution (CC BY) license (http://creativecommons.org/licenses/by/4.0/). 